\title{
Decadal Variation of Atmospheric Rivers in Relation to North Atlantic Tripole SST Mode
}

\author{
Jie Zhang ${ }^{1}$, Yinglai Jia ${ }^{1,2, * \mathbb{D}}$, Rui Ji ${ }^{1}$ and Yifei $\mathrm{Wu}^{3,4}$ \\ 1 Physical Oceanography Laboratory, Ocean University of China, Qingdao 266100, China; \\ zj8080@stu.ouc.edu.cn (J.Z.); jirui@stu.ouc.edu.cn (R.J.) \\ 2 Pilot National Laboratory for Marine Science and Technology (Qingdao), Qingdao 266100, China \\ 3 Quanzhou Meteorological Bureau, Quanzhou 362000, China; 13061383900@163.com \\ 4 Fujian Key Laboratory of Severe Weather, Fuzhou 350001, China \\ * Correspondence: jiayingl@ouc.edu.cn
}

check for updates

Citation: Zhang, J.; Jia, Y.; Ji, R.; Wu, Y. Decadal Variation of Atmospheric Rivers in Relation to North Atlantic Tripole SST Mode. Atmosphere 2021, 12, 1252. https://doi.org/10.3390/ atmos12101252

Academic Editors: Mengqian Lu and Mengxin Pan

Received: 29 August 2021

Accepted: 24 September 2021

Published: 27 September 2021

Publisher's Note: MDPI stays neutral with regard to jurisdictional claims in published maps and institutional affiliations.

Copyright: (c) 2021 by the authors. Licensee MDPI, Basel, Switzerland. This article is an open access article distributed under the terms and conditions of the Creative Commons Attribution (CC BY) license (https:/ / creativecommons.org/licenses/by/ $4.0 /)$.

\begin{abstract}
The North Atlantic tripole (NAT) is the leading mode of sea-surface temperature (SST) in the decadal time scale. Although the NAT is forced by North Atlantic oscillation (NAO), it also has an effect on the atmosphere; for example, the early winter tripole SST signal can influence storm tracks in March. As the NAT not only changes the baroclinicity of the lower layer but also modifies the moisture being released into the atmosphere, we surmise that the NAT has an impact on moisture transport and atmospheric rivers in the decadal time scale. Using ERA5 reanalysis data, the decadal variations in Atmospheric Rivers (ARs) in the North Atlantic in boral winter in relation to NAT phases were studied. During the positive NAT phase, the positive SST in the central and western North Atlantic increases the humidity and causes an anticyclonic wind response, which enhances the northeastward transport of moisture. As a result, ARs tend to be longer and transport more moisture toward northwestern Europe. This causes enhanced extreme rain in the UK and Norway. During the negative NAT phase, the positive SST anomalies in the south and east of the North Atlantic provide more moisture, induce a southward shift of the ARs and enhance extreme rain in the Iberian Peninsula. The Gulf Stream (GS) front is stronger during the negative NAT phase, increasing the frequency of the atmospheric front and enlarging the rain rate in ARs.
\end{abstract}

Keywords: North Atlantic tripole SST signal; atmospheric river; extreme precipitation; western Europe

\section{Introduction}

Atmospheric rivers are long, narrow water vapor transport bands and they are a major means by which water vapor can be transported in mid-latitudes [1]. Due to their large amount of water vapor, ARs can cause precipitation and flooding when making landfall, especially in the mountainous regions [2]. North Atlantic ARs have a significant impact on severe rainfall, responsible for approximately $20-30 \%$ of all precipitation in parts of western Europe [3]. For example, in Norway, Scotland and the Iberian Peninsula, most extreme daily precipitations are associated with ARs [4-6]. Atmospheric rivers are closely related to extratropical cyclones (ECs) and are often identified in the warm sector of ECs and some studies specifically consider ARs to be portions of the EC system [7]. As the storm tracks are affected by the ocean, such as the SST variations, the occurrence of ARs is also found to be influenced by both large-scale SST variations [8] and mesoscale SST anomalies [9].

In the interannual-decadal time scale, variation in ARs and extreme precipitation in western Europe are reported to be affected by the North Atlantic oscillation (NAO). Under negative North Atlantic oscillation (NAO) conditions, southern Europe is most affected by ARs, while AR landfall in northern Europe is more associated with positive $\mathrm{NAO}$ [5]. As the direct response of the ocean mixed layer to NAO [10], the North Atlantic tripole (NAT) distribution is the leading mode of SSTs in the decadal time scale [11,12]. 
In the multidecadal time scale, the ocean response to NAO shows a monopole SST pattern, with an estimated period of 60-80 years, which is known as the Atlantic Multidecadal Oscillation (AMO) [13,14]. The AMO modulates the NAO variation and the relationship between north Atlantic SST anomalies and storm tracks $[13,15]$. Leading by several months, the tripole SST anomalies positively affect NAO $[16,17]$. The early winter (NovemberDecember) tripole SST signal can change the lower tropospheric baroclinicity and influence storm tracks in March [15]. As ARs are closely related to storm tracks, does the NAT have an impact on ARs?

Although the NAT is the ocean response of NAO, from the time series of the two, between 1980 to 2020 (Figure 1a), we noted that the NAT variation considerably differs from that of NAO. First, NAO essentially varies in an interannual mode, while the NAT mainly varies in the decadal time scale. For example, during the 40 years from 1980 to 2020, the NAT showed a decadal variation, with the positive and negative NAT phases beginning from 1982 and 1995 and ending in 1996 and 2012 (Figure 1a), respectively, while NAO mainly showed an interannual variation (Figure 1c). Second, from the EOF1 distribution of NAT mode (Figure 1b), we noted a positive SST signal spreading along the GS ocean front. This suggests a difference in the GS front between the two NAT modes, which may also induce the response of ARs in the North Atlantic, as suggested in the work conducted by Wu et al. [18]. The ARs induce extreme rain during landfall in western Europe; for example, the $95 \%$ extreme rainfall in Norway and the UK shows much higher and lower occurrence tendency during NAT+ and NAT- modes (Figure 1d), respectively. Is this decadal change in extreme rainfall related to the different behavior of ARs in NAT+ and NAT - modes? With the aim of addressing these research questions, we are interested in studying the decadal variation in ARs related to the NAT.

(a)

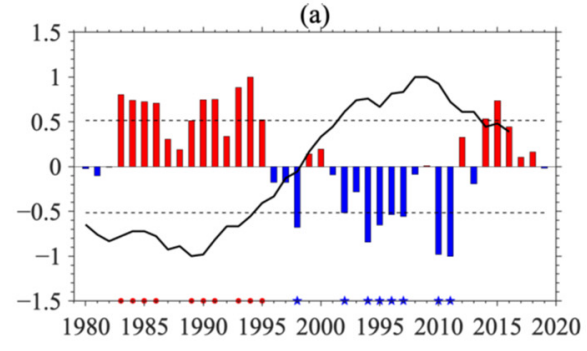

(c)

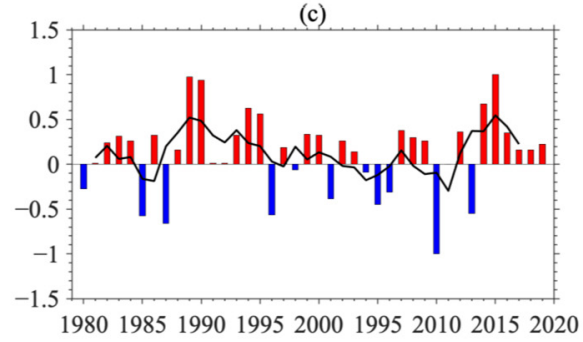

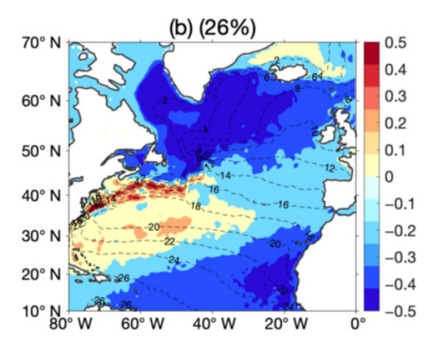

(d)

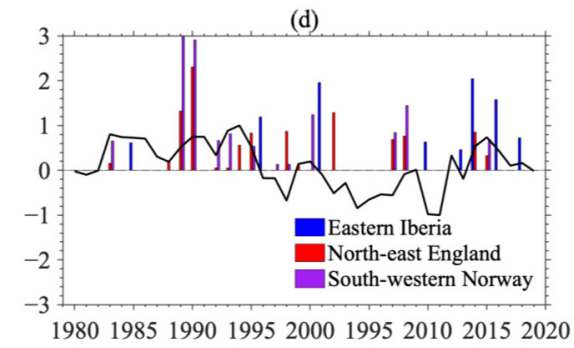

Figure 1. (a) Standardized time series of leading EOF of winter (JFM) SST showing NAT index from 1980 to 2019 (bar). The AMO index is overlapped using a solid black line. The positive-phase years are 1983-1986, 1989-1991 and 1993-1995 (red dots) and the negative phase years are 1998, 2002-2006 and 2010-2011 (blue stars). (b) Leading EOF showing tripole SST distribution. Dashed contours are climatological SSTs. (c) Time series of NAO index (bars) with 4-year running mean (solid black line). (d) Bars show the time series of extreme precipitation $(\mathrm{mm} / \mathrm{d})$ in eastern Iberia, northeast England and southeastern Norway (averaged in the black boxes in Figure 5f; higher than the 95th percentile). The black line is the NAT index.

To investigate the decadal variation in ARs related with the NAT, we selected 10 years during each NAT mode for a composite study. Then, we verified the difference in storm tracks, zonal jet, AR occurrence and precipitation in western Europe between the NAT+ 
and NAT - modes. The effect of the GS front on ARs was also investigated. This paper is laid out as follows: In Section 2, the data and methods are provided. In Section 3, we show the decadal variation in ARs related to the NAT and explain the reason via analysis of the background atmospheric circulation. In Section 4, we compare the characteristics of ARs and investigate the influence of the Gulf Stream ocean front on ARs during NAT+ / - mode. In Section 5, the conclusion is provided. The effect of the NAO and AMO on the decadal variation in ARs is also discussed in Section 5.

\section{Data and Methods}

\subsection{Data}

This article uses the ERA5 reanalysis datasets with a $0.25^{\circ} \times 0.25^{\circ}$ spatial resolution. To investigate the effect of the NAT on ARs, we chose to study the boral winter (JFM). Variables such as the velocity, temperature, precipitation, surface-sensible heat flux and vertically integrated moisture flux were retrieved with $6 \mathrm{~h}$ temporal intervals. The period 1980-2019 (40 years) was used for the analyses. A 2-15-day bandpass filter was applied to obtain the anomaly of velocity in order to calculate the eddy kinetic energy (EKE) for synoptic variation.

\subsection{The NAT, NAO and AMO Index}

To focus on the decadal variation of SSTs in the North Atlantic, firstly, we obtained yearly SST data by averaging each three months in boral winter (JFM). Then, following $[10,19]$, the NAT pattern was defined as the first empirical orthogonal function (EOF) of that yearly SST over the region $\left(10^{\circ} \mathrm{N}-70^{\circ} \mathrm{N}, 80^{\circ} \mathrm{W}-0^{\circ} \mathrm{E}\right)$, after the linear trend was removed. The principle component time series of that first EOF mode is the NAT index.

The NAO Index data were provided by the Climate Analysis Section, NCAR, Boulder, USA, using the definition developed by Hurrell et al. [20] and the AMO Index data derived from HadISST using Trenberth and Shea's definition [14]. The index data were retrieved from https: / / climatedataguide.ucar.edu/climate-data/hurrell-north-atlantic-oscillationnao-index-station-based (accessed on 25 August 2021) and https: / climatedataguide.ucar. edu/climate-data/atlantic-multi-decadal-oscillation-amo (accessed on 25 August 2021).

\subsection{AR Detection and Composition}

There are many ways to capture ARs, but many scholars have accepted the value of vertically integrated water vapor transport (IVT) as the criterion [21]. Using the vertical integral of eastward and northward water vapor flux from the ERA5 reanalysis, we calculated IVT using the following formula:

$$
\mathrm{IVT}=\sqrt{\left(\frac{1}{\mathrm{~g}} \int_{1000}^{300} \mathrm{qudp}\right)^{2}+\left(\frac{1}{\mathrm{~g}} \int_{1000}^{300} \mathrm{qvdp}\right)^{2}}
$$

where $\mathrm{p}$ is the pressure of atmosphere, $\mathrm{q}$ is the specific humidity, $\mathrm{u}$ is the zonal wind, $\mathrm{v}$ is the meridional wind and $\mathrm{g}$ is the acceleration due to gravity.

Then, the IVT threshold was selected as an abnormal value of $250 \mathrm{~kg} \mathrm{~m}^{-1} \mathrm{~s}^{-1}$. Structures longer than $2000 \mathrm{~km}$ and narrower than $1000 \mathrm{~km}$ were detected as ARs [22]. We detected 5000+ ARs from the $6 \mathrm{~h}$ data during NAT-positive and -negative years. The AR occurrence frequency is defined as the number of days with an AR divided by the total number of days for study on each grid. ARs were designated as landfalling if the outmost contour intersected the coastline. The frequency of landfalling ARs was calculated using the same method as the AR occurrence frequency.

In order to analyze the individual characteristics of ARs in more detail, we used the polar coordinate interpolation method $[23,24]$ to obtain the composite field of ARs. Prior to the composite, all variables were stretched to a standardized coordinate system with common centers, interpolated into a grid of $100 \times 100$ and $R$ represents 1 time the AR-long axis. 


\subsection{Atmospheric Fronts Detection}

To detect the atmospheric fronts and examine their relationship with ARs, following the work conducted by Parfitt et al. [25], we calculated the frontal variable $F^{*}$ of $900 \mathrm{hpa}$ :

$$
F *=\zeta_{900 \mathrm{hPa}}\left|\nabla\left(T_{900 \mathrm{hPa}}\right)\right|,
$$

where $\zeta$ is the relative vorticity and $T$ is the temperature of the atmosphere. Then, $F^{*}$ was divided by typical scales to obtain the nondimensional value $F$ :

$$
F=F * /\left(\mathfrak{f}|\nabla T|_{0}\right),
$$

where $|\nabla T|_{0}=0.45 \mathrm{~K} /(100 \mathrm{~km})$ and $\mathrm{f}$ is the Coriolis parameter value of the relevant latitude. Regions with $F \geq 1$ were defined as the atmospheric front.

\section{Decadal Variation of ARs in Relation to the NAT}

The first mode of the EOF of North Atlantic SSTs (which explains 26\% of the total variance) showed a positive SST anomaly near the southeastern coast of the United States and two negative anomalies in the east of Newfoundland and in the tropical eastern Atlantic (Figure 1b). This percentile of the first EOF agrees with former studies [26,27]. Although the percentile of this NAT mode was not very high, it could force a NAO-like pattern, which explains $47.7 \%$ of the $500 \mathrm{hPa}$ geopotential variance [26]. It could influence the storm tracks in March [16]. It was also an important part in the quasi-60 year circle of the NAO-AMO coupled mode [27]. From its time series (Figure 1a), the first mode was in the positive phase (NAT+) during the period 1982-1996 and in the negative phase (NAT-) from 1995 to 2012, exhibiting significant decadal variation. The distribution and time series of the NAT agree with those observed by Fan and Schneider [11]. To compare the difference in the ARs during the two NAT modes, we chose the years in which the NAT index was higher than one standard deviation to represent NAT+ mode years (1983-1986, 1989-1991 and 1993-1995) and NAT - mode years (1998, 2002-2006 and 2010-2011) for composite analysis (the red and blue marks in Figure 1a). From the EOF1 pattern of the NAT (Figure 1b), we noted a positive SST signal spreading along the GS ocean front. To explore whether this positive SST signal strengthened or weakened the ocean front, we plotted the SST gradient difference between NAT+/- years (Figure 2a,b). It can be observed that, along the upper stream of the GS extension, the SST gradient was smaller in NAT+ years (Figure 2b). The profile of the zonal-averaged (between $65^{\circ} \mathrm{W}$ and $55^{\circ} \mathrm{W}$ ) SST gradient shows an increase in ocean front between $40^{\circ} \mathrm{N}$ and $42^{\circ} \mathrm{N}$ during NATyears, which agrees with the finding in Wu et al. [18]. The effect of this SST gradient variation on ARs is discussed in Section 4.

To investigate the decadal variation in ARs in the North Atlantic, we compared the composite distribution of the mean IVT, EKE and occurrence of ARs between the NAT+ and NAT - years. From Figure 3, the maximum IVT distributed along the south of the GS front in both NAT+ / - years. During NAT+ years, the IVT spread from the southwest straight forward to the northeast, while the IVT remained south of the GS front during NAT - years. The EKE fields show similar features. The centers of the EKE were located to the north of the IVT, because the moisture transport was mainly distributed in the south of the ECs [28]. A clear northward shift in the IVT and EKE can be seen in NAT+ years (Figure 3). 

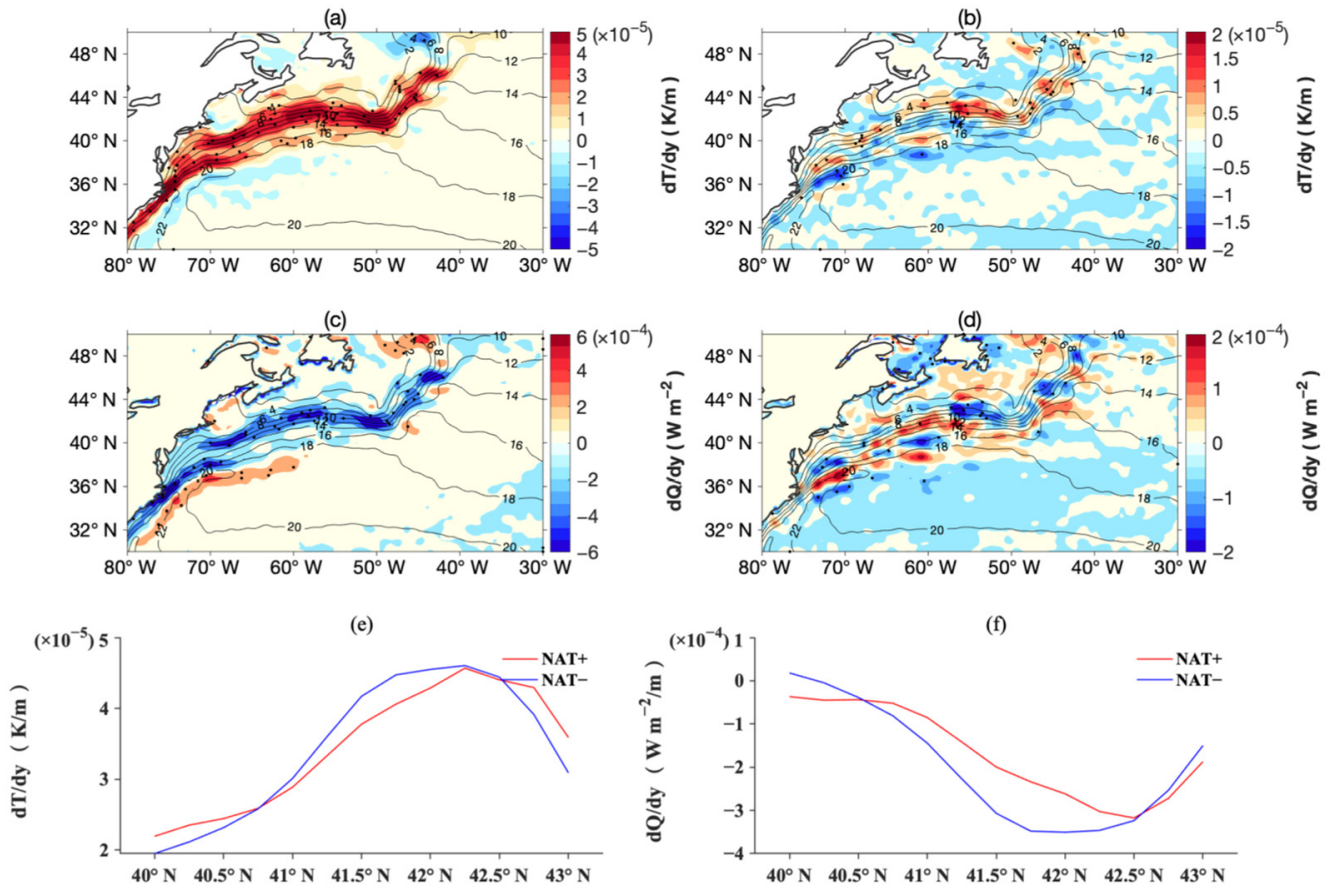

Figure 2. (a) Colors are SST gradients $(\mathrm{dT} / \mathrm{dy})$ in NAT+ phase $(\mathrm{K} / \mathrm{m})$. Contours are mean SSTs in NAT + phase $\left({ }^{\circ} \mathrm{C}\right)$. (b) Difference in dT/dy between NAT + and NAT - phases. Contours are mean SSTs in NAT - phase. (c) Air-sea sensible heat flux gradient $(\mathrm{dQ} / \mathrm{dy})$ in NAT+ phase $\left(\mathrm{W} \mathrm{m}^{-2}\right)$. Contours are the same as in (a). (d) Difference in dQ/dy between $\mathrm{NAT}+$ and NAT - . Contours are the same as in (b). (e) Meridional distribution of dT/dy averaged between $55^{\circ} \mathrm{W}$ and $65^{\circ}$ W. (f) Same as (e) but for dQ/dy.
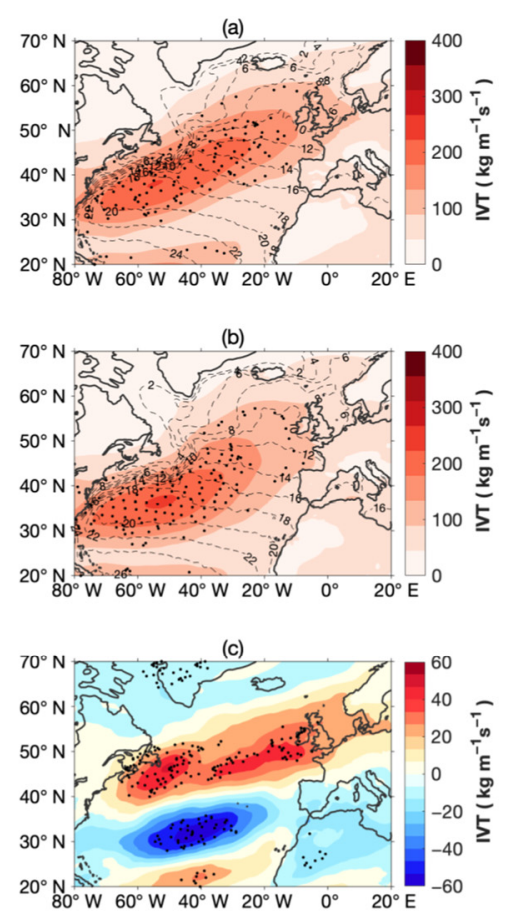
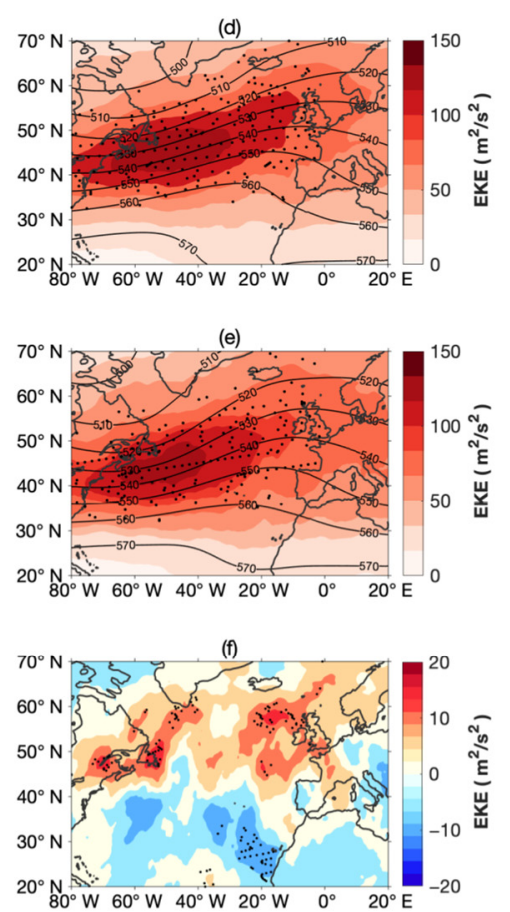

Figure 3. (a) Distribution of IVT (colors, $\mathrm{kg} \mathrm{m}^{-1} \mathrm{~s}^{-1}$ ) and mean SSTs (contours, ${ }^{\circ} \mathrm{C}$ ) in NAT+ phase. (b) IVT (color) and SSTs (contour) in NAT - phase. (c) Difference in IVT (color) in NAT+ and NATphases. Black dots mark those above $95 \%$ confidence level based on a Student's $t$-test. Right column $(\mathbf{d}-\mathbf{f})$ is same as the left but for $\mathrm{EKE}\left(\mathrm{m}^{2} / \mathrm{s}^{2}\right)$ on $300 \mathrm{hPa}$ and contours are Z500 (10 m). 
The AR occurrence frequency is similar to the distribution of the IVT. During NAT+ years, ARs spread from the south of the GS front toward the UK during NAT+ years (Figure 4), while during NAT - years, ARs were more confined to the south of the GS front. The AR occurrence frequency increased by about $6 \%$ in north Europe and decreased by more than $6 \%$ south of the GS front, which is about one quarter of the total, suggesting a significant influence of the NAT on ARs. To investigate why ARs had more of an influence on northern Europe during NAT+ years, we checked the length of ARs in the two scenarios. As shown in Figure 4d, the length of ARs was mainly 20-60 degrees. ARs tend to be longer and shorter during NAT+ and NAT - years, respectively. Thus, during NAT+ years, the ARs spread in a more straightforward manner from the south of the GS front toward western Europe.
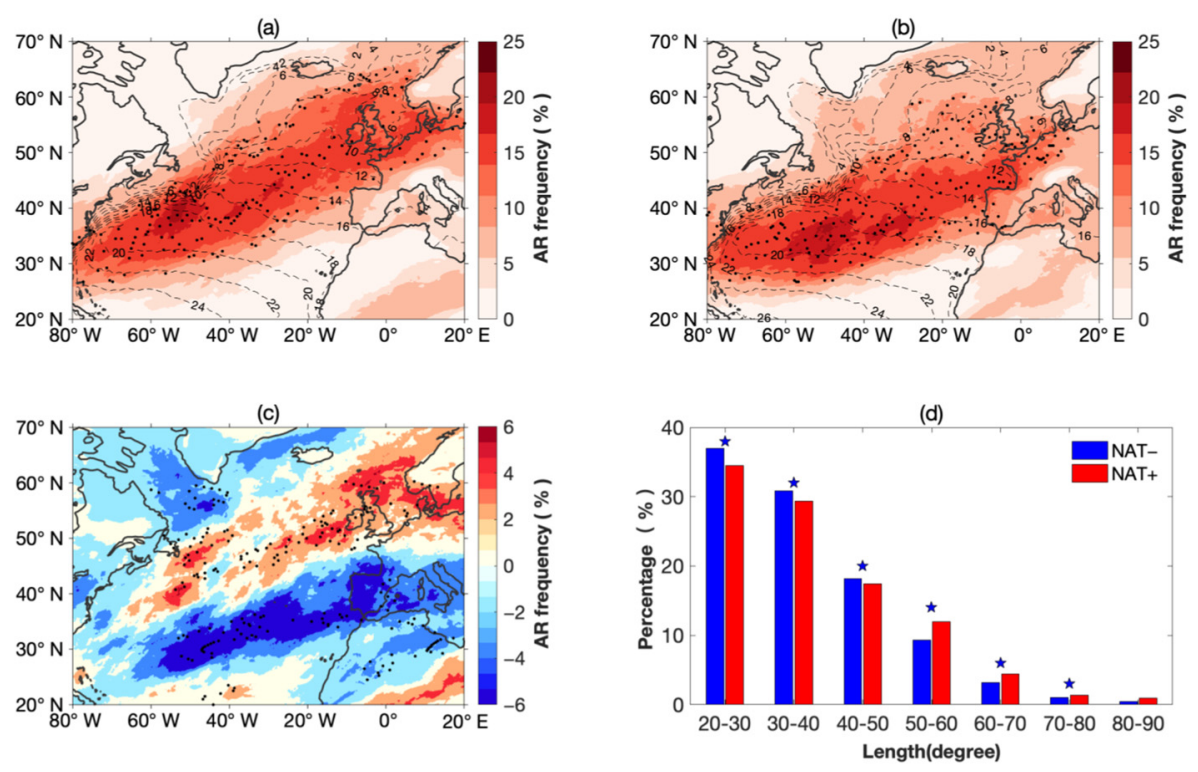

Figure 4. (a) AR occurrence frequency (colors, \%) and mean SST (contours, ${ }^{\circ} \mathrm{C}$ ) in NAT+ phase. (b) AR occurrence frequency (colors) and mean SST (contours) in NAT- phase. (c) The difference in AR occurrence frequency in NAT+ and NAT - phases (color). Black dots mark those above 95\% confidence level based on a Student's $t$-test. (d) Histogram of the percentage of the length (in degree) of ARs. A difference above $95 \%$ confidence level based on a Student's $t$-test is marked by the blue stars over the bar.

As ARs encounter the western coast of Europe, which is also called landfalling of ARs [1], large amounts of water vapor are transported and extreme precipitation is induced. In regions of western Europe, such as the UK, Norway and Iberia Islands, most extreme rainfall is reported to be connected by landfalling ARs [5]. Figure 5 shows the frequency of landfalling ARs. The difference between the landfalling frequency is significant; during NAT+ years, the frequency increased by 3\%, which is half of the total. The landfall caused by ARs induced heavy rain in western Europe. It is clear that more precipitation affected northern Europe during NAT+ years when ARs were longer and moving straight northeastward. The rain rate increased by more than half in the UK and Norway, while it decreased significantly in Iberia Islands during NAT+ years. The increase in extreme rainfall agrees with Figure 1d, which shows higher occurrence of $95 \%$ extreme rain in the UK and Norway during NAT+ years, while during NAT - years, more extreme rain occurred in Portugal can be observed. Thus, it can be stated that it is the northward shift in the AR landfall location that caused the increase and decrease in extreme rain in the UK and Portugal, respectively, during NAT+ years. This raises the following question: what caused the change in the AR landfall locations? 

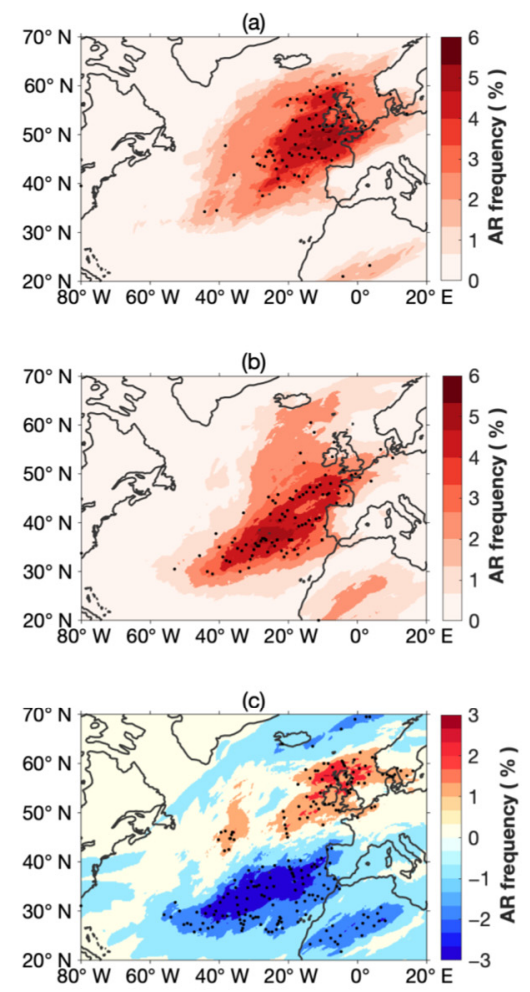
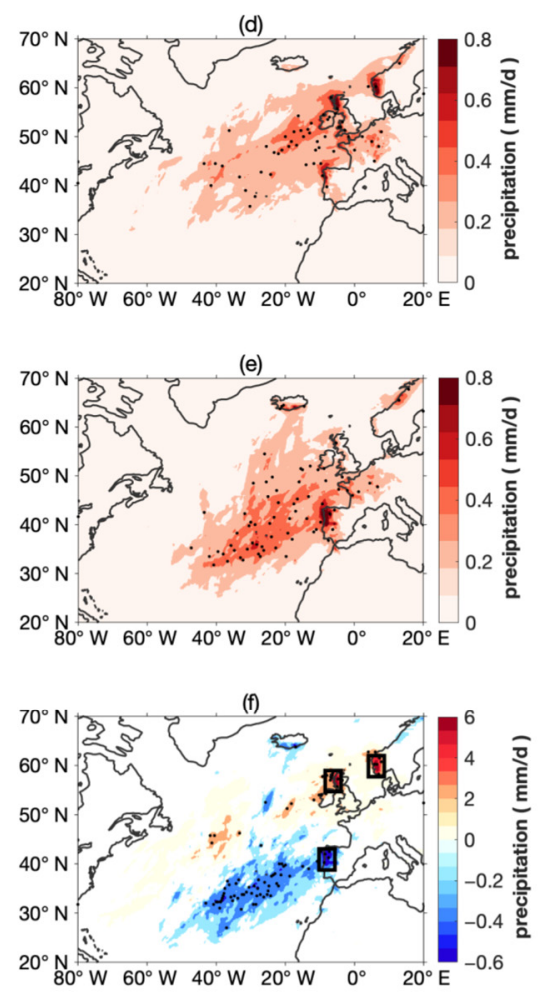

Figure 5. (a) Distribution of AR landfalling frequency in NAT+ phase. (b) AR landfalling frequency in NAT - phase. (c) Difference: black dots mark the difference above 95\% confidence level based on a Student's $t$-test. Right column $(\mathbf{d}-\mathbf{f})$ is the same as the left but for AR-related precipitation (mm/d). Black boxes in (f) are regions that are averaged to obtain the time series of extreme precipitation in eastern Iberia, northeast England and southeastern Norway.

As the NAT is closely related to the NAO, first, we examined the literature on NAOrelated atmospheric circulations. The positive NAO mode leads to enhanced westerly flow, poleward shift in the jet stream and a northward shift of the mid-latitude storm track [29-31]. Seager et al. [32] studied the relationship between precipitation in western Europe and NAO and they found that for, a positive NAO, anomalous moist advection induced enhanced precipitation in northwestern Europe and drying in southwestern Europe. Ummenhofer et al. [33] found that the north increase-south decrease pattern of rain distribution in western Europe is related to a positive SST anomaly in the central Atlantic. This gives rise to the following question: how is atmospheric circulation variation related to the NAT?

In order to investigate the background flow during the NAT+ / - phases, the composite maps of zonal wind on $300 \mathrm{hPa}$, geopotential on $500 \mathrm{hPa}$ and vertically integrated water vapor transport are shown in Figure 6. During NAT+ phases, the jet stream on $300 \mathrm{hPa}$ was stronger than that during NAT- phases. The geopotential on $500 \mathrm{hPa}$ showed a larger trough during NAT- phases, which is associated with a jet that was increased south of the GS but decreased in the eastern part of the Atlantic. This distribution of the jet stream agrees with the pattern of storm tracks (Figure 3e), in which, during NAT - phases, the storms were more confined to the south of the GS. As NAT+ years were also present in the NAO-positive phase, the background flow features above might be the combined effect of the two variations. 

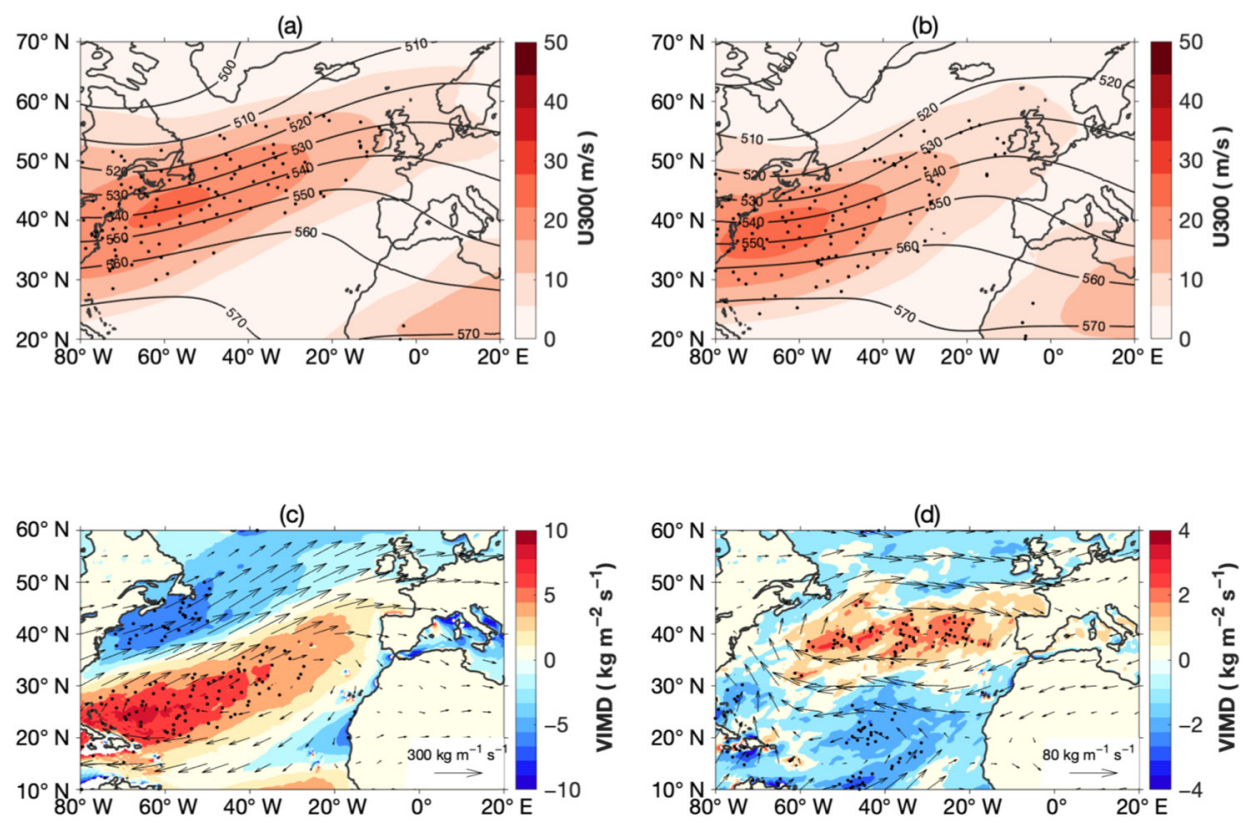

Figure 6. (a) Colors are distribution of $\mathrm{U}$ on $300 \mathrm{hPa}$ (colors, $\mathrm{m} / \mathrm{s})$ and $\mathrm{Z}$ on $500 \mathrm{hPa}(10 \mathrm{~m}$, contours) in NAT+ phase. (b) Same as (a) but for NAT - phase. (c) Colors are distribution of VIMD $\left(\mathrm{kg} \mathrm{m}^{-2} \mathrm{~s}^{-1}\right)$ in NAT+ phase. Vectors are vertical integral water vapor flux $\left(\mathrm{kg} \mathrm{m}^{-1} \mathrm{~s}^{-1}\right)$ in NAT+ phase. (d) Difference in VIMD (color) and vertical integral water vapor flux (vectors) between NAT+ and NAT - phases. Black dots mark the difference above 95\% confidence level based on a Student's $t$ test.

As suggested by Ramos et al. [34], the moisture source of ARs is not only the local ocean surface but also the tropical region. To verify the moisture source during NAT+/phases, we plotted vertically integrated moisture divergence (VIMD) in Figure 6, which indicates the moisture source according to the work of Gimeno et al. [35]. In agreement with this, the positive VIMD was located south of $30^{\circ} \mathrm{N}$. Associated with the jet stream and EKE distribution, the positive VIMD spread further northeastward during the NAT+ phase. To explain how the NAT affected the moisture transport, we plotted regressed maps of moisture and wind anomaly on the NAT index (Figure 7a,b). It can be observed that, during the NAT+ phase, the wind anomaly on $850 \mathrm{hPa}$ formed an anticyclone between $20^{\circ} \mathrm{N}$ and $50^{\circ} \mathrm{N}$, agreeing with the work of Souza and Cavalcanti [36] and Seager et al. [32], when the NAO-positive phase was presented. In Figure 7b, the regressed map of humidity on the NAT shows an increased and decreased specific humidity west and east of the Atlantic during the NAT+ and NAT - phases, respectively, also corresponding with the positive and negative SST anomalies, respectively. This humidity anomaly pattern, together with the anticyclonic wind anomaly, increased the positive VIMD along $30^{\circ} \mathrm{N}$ and transported more moisture northeastward during the NAT+ phase. This explains why IVT and ARs are strong and extended more northward. During the NAT - phase, the positive humidity anomaly lay to the west of Iberia Island, confined the moisture source in south of $30^{\circ} \mathrm{N}$ and enhanced rain in southern Europe.

In summary, during the NAT+ phase, the trough of Z500 is weaker and the subtropical jet is stronger, which induces the northward shift of the storm track and AR frequency. During the NAT - phase, water vapor is confined to the south of the GS front due to the weakened trade wind and northward moisture transport, resulting in the enhancement of ARs in the south of the GS front. Meanwhile, due to the strong trough of Z500, the subtropical jet is shorter and less ARs can affect northern Europe. 

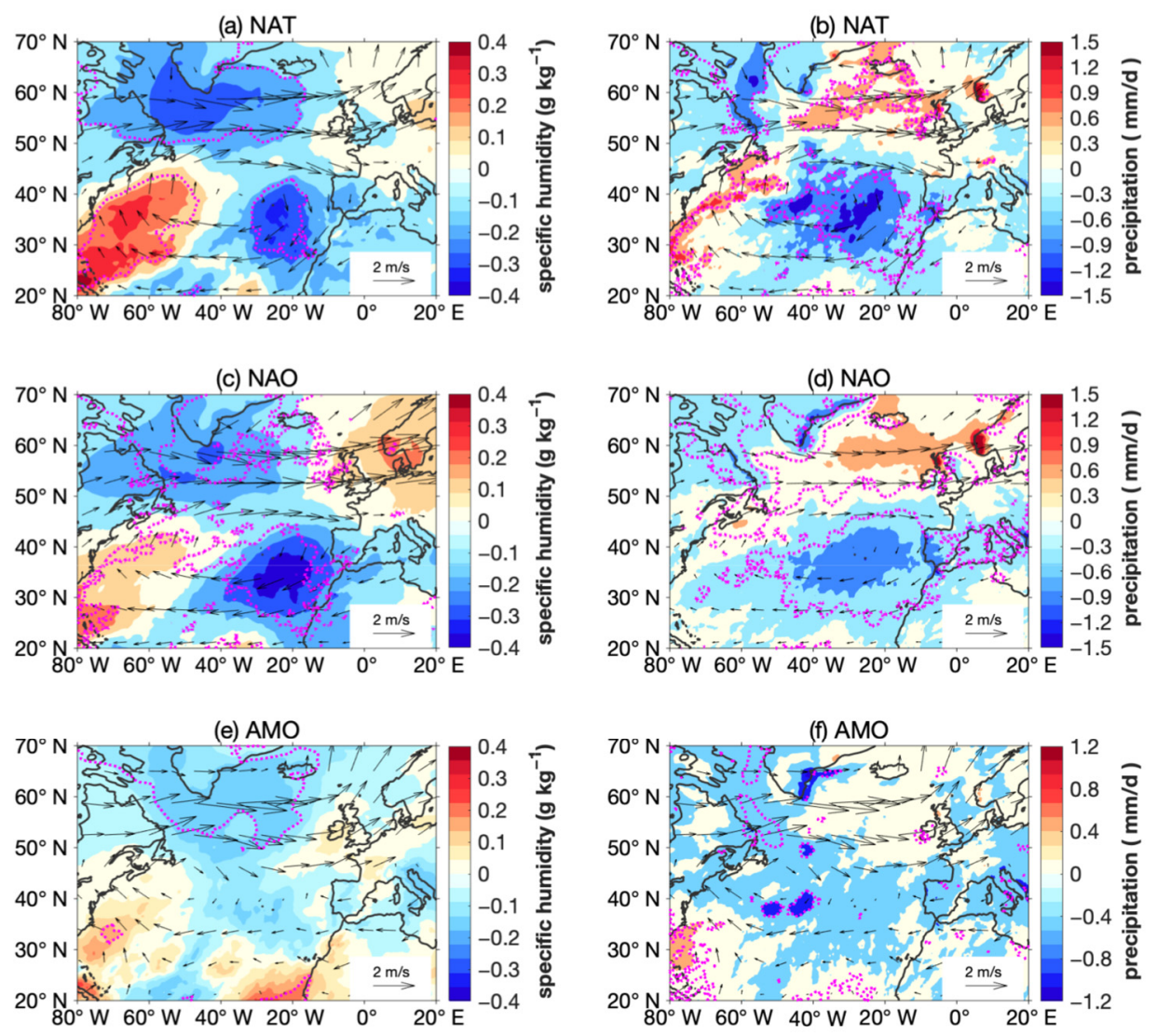

Figure 7. (a) Regression of specific humidity on $850 \mathrm{hPa}$ (colors, $\mathrm{g} \mathrm{kg}^{-1}$ ) and wind velocity on $850 \mathrm{hPa}$ (vectors, $\mathrm{m} \mathrm{s}^{-1}$ ) on NAT index. The second row $(\mathbf{c}, \mathbf{d})$ and third row $(\mathbf{e}, \mathbf{f})$ are the same as the first row $(\mathbf{a}, \mathbf{b})$ but for regression on NAO and negative AMO index, respectively. Purple contours mark the signal above $95 \%$ significance level.

\section{The Influence of the GS Ocean Front on ARs during NAT Phases}

As shown in the study conducted by Darce et al. [7], ARs often form in the southern part of an AR when both the cold and warm fronts are present. As ARs more frequently occur to the south of the GS front, there should be a higher chance of an atmospheric front that is associated with ARs' encounter with the GS front. As suggested by Parfitt et al. [37], a strong vertical flow forms when the atmospheric front interacts with the ocean front, resulting in strong upward movement and precipitation, which is called the thermal damping and strengthening (TDS) mechanism. Specifically, dQ/dy $<0$ in the GS front means that the sensible heat flux gradient across the GS strengthens the atmospheric front in this area. As is shown in Figures 1 and 2, during the NAT+ phase, the SSTs are greater in the GS region and the ocean front is weaker. In Figure 2e,f, the zonal-averaged $\mathrm{dQ} / \mathrm{dy}$ and SST gradient (dT/dy) between $65^{\circ} \mathrm{W}$ and $55^{\circ} \mathrm{W}$ shows a strong SST gradient and low $\mathrm{dQ} / \mathrm{dy}$, suggesting a stronger ocean front and TDS mechanism during the NAT - phase.

To investigate the relationship between ARs and atmospheric fronts, as well as the variation in ARs during the two NAT phases, a composite analysis was performed. We constructed the composite patterns from 2200+ (2000+) ARs during NAT+ (NAT-) years from the 6-h data. In Figure 8, the shading is the composite IVT for ARs and the isolines are the SLP anomaly. As expected, there was a negative SLP center northwest of the ARs, showing the close relationship between an EC and an AR. During the NAT+ phase, the cyclone was strong, while, during the NAT - phase, the cyclone was weak but the positive SLP anomaly in the east was stronger, corresponding with the larger ridge in Z500 in the NATphase. Compared with that during the NAT - phase, the IVT in ARs were shifted northward, agreeing with the AR frequency distribution during the NAT+ phase. The humidity 
in ARs showed a significant northward shift. This is because the positive SST anomalies in the south and east increased the humidity during the NAT - phase (Figure 7a), supplying more moisture to the ARs in the south.
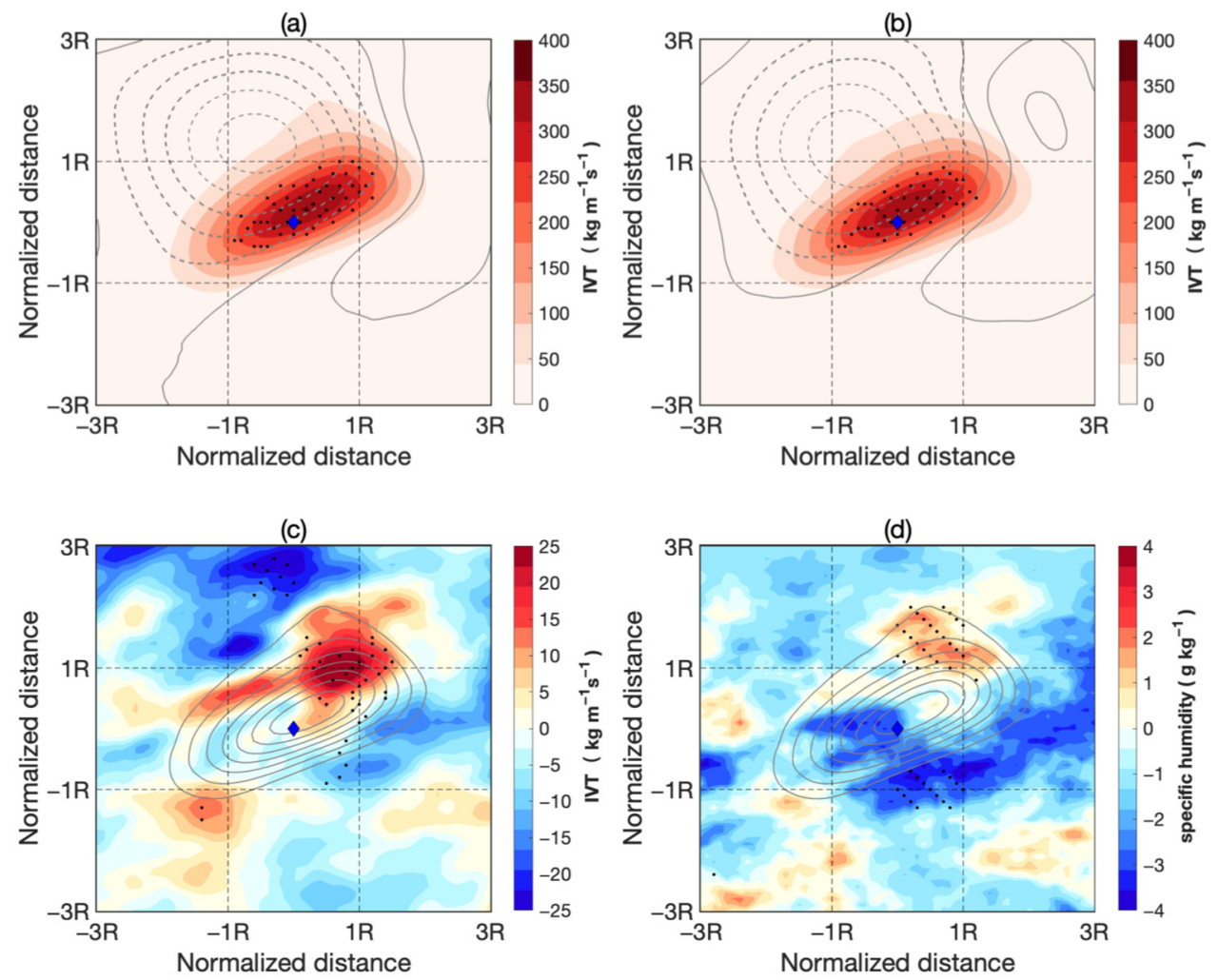

Figure 8. (a) Composite of IVT (color, $\mathrm{kg} \mathrm{m}^{-1} \mathrm{~s}^{-1}$ ) and SLP anomalies (contours in interval of $1 \mathrm{hpa}$ ) in ARs during NAT+ phase. (b) Same as (a) but for NAT - phase. (c) Difference in IVT (color) between NAT+ and NAT - phases. Contours are IVT in NAT+ phase from 50 to 350 with the interval of $50 \mathrm{~kg} \mathrm{~m}^{-1} \mathrm{~s}^{-1}$. Black dots mark those above $95 \%$ confidence level based on a Student's $t$-test. (d) Same as (c) but for specific humidity on $850 \mathrm{hPa}\left(\mathrm{g} \mathrm{kg}^{-1}\right)$. The blue diamond in each sub-figure marks the center of the domain. $R$ on the axes is the normalized length of ARs. The range of AR length is shown in Figure $4 \mathrm{~d}$. The length of more than $60 \%$ of ARs is within 40 degrees (which is about $4000 \mathrm{~km})$.

Figure 9 shows the relationship between ARs and atmospheric fronts. From the composite maps of the occurrence frequency of the atmospheric front and AR-related precipitation, the atmospheric front was mainly distributed in the north and east of the ARs, agreeing with the relative location of the atmospheric front and ARs in the work of Dacre et al. [7]. During the NAT - phase, the frequency of the atmospheric front increased near the center of ARs, which is related to the low dQ/dy and strong TDS mechanism shown in Figure 2. The precipitation was located near the atmospheric front, because when the atmospheric front encounters the ocean front, the upward flow is increased and more rain is induced [37]. During the NAT - phase, the precipitation in the AR central region also increased, together with the increase in the atmospheric front frequency. The regression of precipitation on the NAT index shows an increased precipitation in the southern and eastern part of the north Atlantic during the NAT - phase (Figure 7b), which is related to the humidity increase (Figure 7a) and agree with the composite result.

In summary, the SST gradient and TDS mechanism at the GS front are stronger during the NAT - phase, which strengthens the atmospheric front and increases precipitation. 
(a)

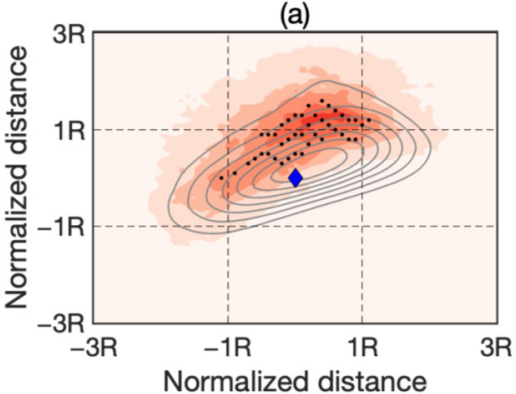

(b)

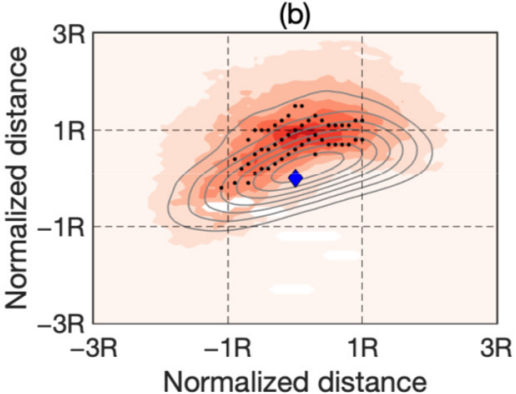

(c)

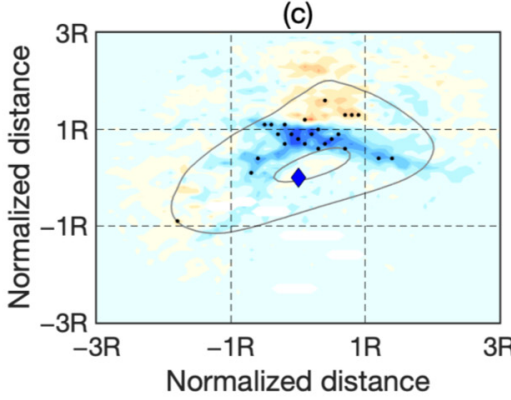

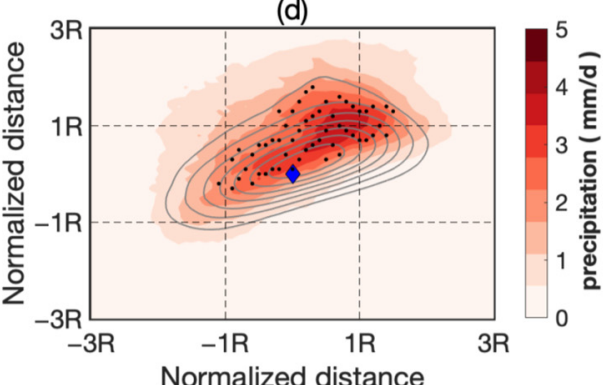

(e)

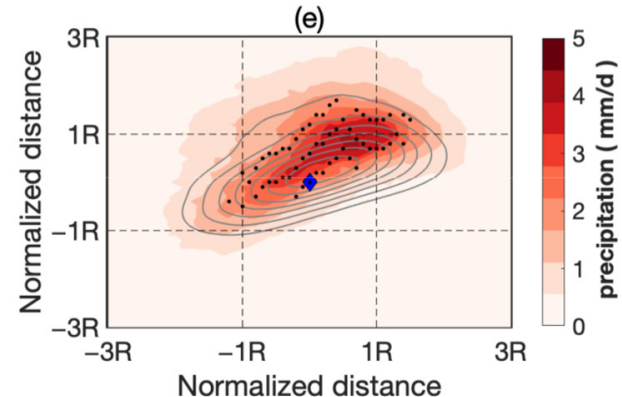

(f)
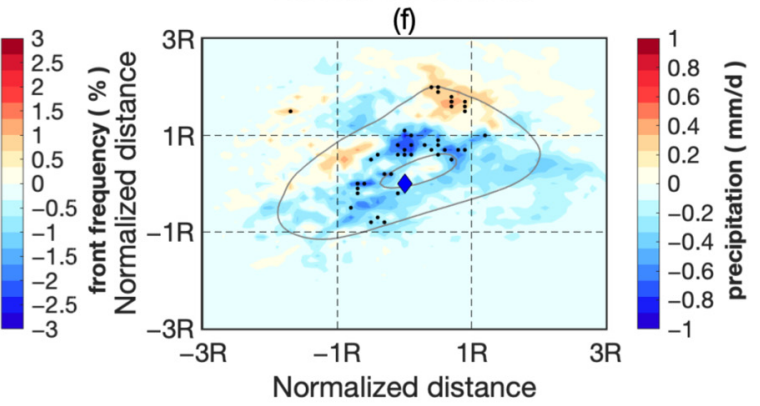

Figure 9. (a) Composite of atmospheric front frequency (color, \%) and IVT (contour, $\mathrm{kg} \mathrm{m}^{-1} \mathrm{~s}^{-1}$ ) in ARs during NAT+ phases. (b) Same as (a) but for NAT - phase. Contours are IVT (contour) in NAT+ phase from 50 to 350 with the interval of $50 \mathrm{~kg} \mathrm{~m}^{-1} \mathrm{~s}^{-1}$. (c) Difference in front frequency (color) between NAT+ and NAT - phases. Contours are IVT of 50 and $350 \mathrm{~kg} \mathrm{~m}^{-1} \mathrm{~s}^{-1}$ showing the range and center of the AR in NAT+ phase. The black dots mark those above $95 \%$ confidence level based on a Student's $t$-test. Right column(d-f) is same as the left but for AR-related precipitation $(\mathrm{mm} / \mathrm{d})$. The blue diamond in each sub-figure marks the center of the domain.

\section{Conclusions and Discussions}

Using ERA5 reanalysis data, the decadal variations in ARs in the North Atlantic in boral winter in relation to NAT phases are studied. During the NAT + period, the positive SST in the central and western North Atlantic increases the humidity and causes an anticyclonic wind anomaly, which enhances the northeastward transport of moisture. As a result, ARs tend to be longer and transport more moisture toward northwestern Europe. This causes enhanced extreme rain in the UK and Norway. During the NAT - phase, the positive SST anomalies in the south and east of the North Atlantic provide more moisture, induce a southward shift in the ARs and enhance extreme rain in the Iberian Peninsula. The GS front is stronger during the NAT - phase, increasing the frequency of the atmospheric front and enlarging the rain rate in ARs.

These results indicate that the influence of the NAT on ARs is mainly achieved by increasing the humidity over positive SST anomalies. This changes the distribution of moisture transport and modifies the occurrence frequency of ARs. As NAT is also highly correlated with $\mathrm{NAO}$ and $\mathrm{AMO}$, we further checked the regression maps of humidity and precipitation on NAO and AMO indexes (Figure 7). Although the negative humidity response near the Iberian Peninsula exists in both NAT and NAO regression maps, the positive humidity response south of the GS front is clearly seen only in that of the NAT 
(Figure 7a). This contributes to the increased rain along the GS front during NAT+ phase (Figure 7b). The northward shift of rain can be seen in the response to the NAO and NAT, but not in response to the AMO. The wind responses to the three indexes are all similar, suggesting similar atmospheric circulation correlated with the three indexes. Thus, the different behavior of ARs during NAT+/ - phases are mainly induced by the difference in the humidity response. The NAT regulates the SST distribution, causes the tripole response in the humidity field and modifies the AR distribution by changing the moisture supply. To this extent, the decadal variations in ARs in this paper are mainly related to the NAT. In the future, numerical experiments are needed to precisely separate and compare the impact of the NAO, AMO and NAT on decadal variation in ARs.

Author Contributions: Conceptualization, Y.J. and J.Z.; processing of raw data, analysis and figures, J.Z., Y.J., R.J. and Y.W.; formal analysis, J.Z. and Y.J.; investigation, J.Z. and Y.J.; methodology, Y.J. and J.Z.; supervision, Y.J.; writing-original draft, Y.J. and J.Z. All authors have read and agreed to the published version of the manuscript.

Funding: This research was funded by the National Natural Science Foundation of China (41975065) and the Shandong Natural Science Foundation Project (ZR2019ZD12).

Institutional Review Board Statement: Not applicable.

Informed Consent Statement: Not applicable.

Data Availability Statement: The ERA5 data was downloaded from https:/ / cds.climate.copernicus. eu/which is accessed in 1 January 2021. The NAO Index data were retrieved from https:// climatedataguide.ucar.edu/climate-data/hurrell-north-atlantic-oscillation-nao-index-station-based (accessed on 25 August 2021). The AMO Index data were retrieved from https:/ / climatedataguide. ucar.edu/climate-data/atlantic-multi-decadal-oscillation-amo (accessed on 25 August 2021).

Acknowledgments: The authors are grateful to the three anonymous reviewers who provided insightful and constructive comments that helped to improve this manuscript.

Conflicts of Interest: The authors declare no conflict of interest.

\section{References}

1. Gimeno, L.; Nieto, R.; Vázquez, M.; Lavers, D.A. Atmospheric rivers: A mini-review. Front. Earth Sci. 2014, 2, 2. [CrossRef]

2. Dettinger, M. Climate change, atmospheric rivers, and floods in California-A multimodel analysis of storm frequency and magnitude changes. J. Am. Water Resour. Assoc. 2011, 47, 514-523. [CrossRef]

3. Gimeno, L.; Dominguez, F.; Nieto, R.; Trigo, R.; Drumond, A.; Reason, C.J.C.; Taschetto, A.S.; Ramos, A.M.; Kumar, R.; Marengo, J. Major Mechanisms of Atmospheric Moisture Transport and Their Role in Extreme Precipitation Events. Annu. Rev. Environ. Resour. 2016, 41, 117-141. [CrossRef]

4. Azad, R.; Sorteberg, A. Extreme daily precipitation in coastal western Norway and the link to atmospheric rivers. J. Geo-phys. Res. Atmos. 2017, 122, 2080-2095. [CrossRef]

5. Lavers, D.A.; Villarini, G. The nexus between atmospheric rivers and extreme precipitation across Europe. Geophys. Res. Lett. 2013, 40, 3259-32644. [CrossRef]

6. Eiras-Barca, J.; Lorenzo, N.; Taboada, J.; Robles, A.; Miguez-Macho, G. On the relationship between atmospheric rivers, weather types and floods in Galicia (NW Spain). Nat. Hazards Earth Syst. Sci. 2018, 18, 1633-1645. [CrossRef]

7. Dacre, H.F.; Martinez-Alvarado, O.; Mbengue, C.O. Linking atmospheric rivers and warm conveyor belt airflows. J. Hydrometeorol. 2019, 20, 1183-1196. [CrossRef]

8. Zhang, W.; Villarini, G. Uncovering the role of the East Asian jet stream and heterogeneities in atmospheric rivers affecting the western United States. Proc. Natl. Acad. Sci. USA. 2018, 115, 891-896. [CrossRef]

9. Liu, X.; Ma, X.; Chang, P.; Jia, Y.; Patricola, C.M. Ocean fronts and eddies force atmospheric rivers and heavy precipitation in western north america. Nat. Commun. 2021, 12, 1268. [CrossRef] [PubMed]

10. Deser, C.; Timlin, M.S. Atmosphere-Ocean Interaction on Weekly Timescales in the North Atlantic and Pacific. J. Clim. 1997, 10, 393-408. [CrossRef]

11. Fan, M.; Schneider, E.K. Observed decadal North Atlantic tripole SST variability. Part I: Weather noise forcing and coupled response. J. Atmos. Sci. 2012, 69, 35-50. [CrossRef]

12. Wu, L.X.; Liu, Z.Y. North Atlantic Decadal Variability: Air-Sea Coupling, Oceanic Memory, and Potential Northern Hemisphere Resonance. J. Clim. 2005, 18, 331-349. [CrossRef]

13. Gastineau, G.; Frankignoul, C. Influence of the North Atlantic SST variability on the atmospheric circulation during the twentieth century. J. Clim. 2015, 28, 1396-1416. [CrossRef] 
14. Trenberth, K.E.; Shea, D.J. Atlantic hurricanes and natural variability in 2005. Geophys. Res. Lett. 2006, 33, L12704. [CrossRef]

15. Gan, B.; Wu, L. Feedbacks of sea surface temperature to wintertime storm tracks in the north atlantic. J. Clim. 2015, 28, 306-323. [CrossRef]

16. Pan, L.-L. Observed positive feedback between the NAO and the North Atlantic SSTA tripole. Geophys. Res. Lett. 2005, 32, L06707. [CrossRef]

17. Czaja, A.; Frankignoul, C. Observed impact of Atlantic SST anomalies on the North Atlantic Oscillation. J. Clim. 2012, 15, 606-623. [CrossRef]

18. Wu, Y.F.; Jia, Y.L.; Ji, R.; Zhang, J. SST Warming in Recent Decades in the Gulf Stream Extension Region and Its Impact on Atmospheric Rivers. Atmosphere 2020, 11, 1109. [CrossRef]

19. Han, Z.; Luo, F.; Wan, J. The observational influence of the North Atlantic SST tripole on the early spring atmospheric circulation. Geophys. Res. Lett. 2016, 43, 2998-3003. [CrossRef]

20. Hurrell, J.W.; Kushnir, Y.; Ottersen, G.; Visbeck, M. The North Atlantic Oscillation: Climatic Significance and Environmental Impact; American Geophysical Union: Washington, DC, USA, 2003; pp. 1-35.

21. Zhu, Y.; Newell, R.E. A proposed algorithm for moisture fluxes from atmospheric rivers. Mon. Weather Rev. 1998, 126, 725-735. [CrossRef]

22. Mundhenk, B.D.; Barnes, E.A.; Maloney, E.D.; Nardi, K.M. Modulation of atmospheric rivers near Alaska and the U.S. West Coast by northeast Pacific height anomalies. J. Geophys. Res. Atmos. 2016, 121, 12751-12765. [CrossRef]

23. Bengtsson, L.; Hodges, K.I.; Keenlyside, N. Will Extratropical Storms Intensify in a Warmer Climate? J. Clim. 2009, 22, 2276-2301. [CrossRef]

24. Catto, J.L.; Shaffrey, L.C.; Hodges, K.I. Can Climate Models Capture the Structure of Extratropical Cyclones? J. Clim. 2010, 23, 1621-1635. [CrossRef]

25. Parfitt, R.; Czaja, A.; Seo, H. A simple diagnostic for the detection of atmospheric fronts. Geophys. Res. Lett. 2017, 44, 4351-4358. [CrossRef]

26. Robertson, A.W.; Mechoso, C.R.; Kim, Y.J. The influence of Atlantic sea surface temperature anomalies on the North Atlantic Oscillation. J. Clim. 2000, 13, 122-138. [CrossRef]

27. Bellucci, A.; Gualdi, S.; Scoccimarro, E.; Navarra, A. NAO-ocean circulation interactions in a coupled general circulation model. Clim. Dyn. 2008, 31, 759-777. [CrossRef]

28. Sun, C.; Li, J.; Jin, F.F. A delayed oscillator model for the quasi-periodic multidecadal variability of the NAO. Clim. Dyn. 2015, 45, 2083-2099. [CrossRef]

29. Rogers, J. North Atlantic storm track variability and its association to the North Atlantic Oscillation and climate variabilit of northern Europe. J. Clim. 1997, 10, 1635-1647. [CrossRef]

30. Hurrell, J.W.; Loon, H.V. Decadal Variations in Climate Associated with the North Atlantic Oscillation. Clim. Chang. 1997, 36, 3-4. [CrossRef]

31. Barnes, E.A.; Hartmann, D.L. Dynamical feedbacks and the persistence of the NAO. J. Atmos. Sci. 2010, 67, 851-865. [CrossRef]

32. Seager, R.; Liu, H.; Kushnir, Y.; Osborn, T.J.; Nakamura, J. Mechanisms of Winter Precipitation Variability in the EuropeanMediterranean Region Associated with the North Atlantic Oscillation. J. Clim. 2020, 33, 7179-7196. [CrossRef]

33. Ummenhofer, C.C.; Seo, H.; Kwon, Y.O.; Parfitt, R.; Brands, S.; Joyce, T.M. Emerging European winter precipitation pattern linked to atmospheric circulation changes over the North Atlantic region in recent decades. Geophys. Res. Lett. 2017, 44, 8557-8566. [CrossRef]

34. Ramos, A.M.; Nieto, R.; Tomé, R.; Gimeno, L.; Trigo, R.M.; Liberato, M.L.; Lavers, D.A. Atmospheric rivers moisture transport from a Lagrangian perspective. Earth Syst. Dynam. Discuss. 2016, 6, 2617-2643.

35. Gimeno, L.; Drumond, A.; Nieto, R.; Trigo, R.; Stohl, A. On the origin of continental precipitation. Geophys. Res. Lett. 2010, 37, L13804. [CrossRef]

36. Souza, P.; Cavalcanti, I. Atmospheric centres of action associated with the Atlantic ITCZ position. Int. J. Climatol. 2010, 29, 2091-2105. [CrossRef]

37. Parfitt, R.; Czaja, A.; Minobe, S.; Kuwano-Yoshida, A. The atmospheric frontal response to SST perturbations in the Gulf Stream region. Geophys. Res. Lett. 2016, 43, 2299-2306. [CrossRef] 